\title{
The EU Approach to Consumer ODR
}

\author{
Emma van Gelder
}

\begin{abstract}
The EU internal market has undergone several developments in the past decades. One of the main developments is the inclusion of a digital dimension. One of the fields in which these developments are very evident is the consumer market. A further development of e-commerce is however hindered because there are no suitable redress mechanisms for consumers involved in low-value, high volume claims typically arising from e-commerce transactions. In response to the ills of existing redress mechanisms, an emerging trend of consumer alternative dispute resolution $(A D R)$ and consumer online dispute resolution $(O D R)$ schemes has been identified throughout the Member States (MS) aimed to offer consumers a swift, cheap and simple procedure through which they can enforce their rightsThis paper outlines the EU approach to Consumer $A D R / O D R$, gives some observations of the functioning of the legislation in practice and concludes with some thoughts for the future.
\end{abstract}

Keywords: consumer alternative/online dispute resolution, European Union, ODR Regulation 524/2013, ADR Directive 2013/11, ODR platform.

\section{General Introduction}

The EU internal market has undergone several developments in the past decades. One of the main developments is the inclusion of a digital dimension. One of the fields in which these developments are very evident is the consumer market. The Internet enables consumers to enter the virtual marketplace choosing from a wide selection of products and to engage in transactions with national as well as international traders. E-Commerce has grown significantly in the past decades and is adopted largely throughout the global marketplace. ${ }^{1}$ Within the EU there is a steady increase in e-commerce, statistics show that in 2018,69\% of Internet users ordered goods and services online. ${ }^{2}$

A further development of e-commerce is however hindered because there are no suitable redress mechanisms for consumers involved in low-value, high volume claims typically arising from e-commerce transactions. This becomes even

* $\quad$ PhD Candidate Erasmus University, Rotterdam. For the purpose of clarity, a 'certified consumer ADR/ODR entity' in this paper means an entity certified under the EU legislative framework.

1 Sutatip Yuthayotin, Access to Justice in Transnational B2C E-Commerce - a Multidimensional Analysis of Consumer Protection Mechanisms, Springer International Publishing 2015, p. 1.

2 European Commission, 'Digital Economy and Society Index Report 2019 Use of Internet Services', p. 11. 
more problematic when the claim has a cross-border dimension, posing additional challenges to access justice within the EU owing to differences in legislation, languages and unfamiliar national procedural rules. ${ }^{3}$ Preventing consumers from enforcing the comprehensive set of EU consumer rights they are entitled to, challenges their fundamental right of access to justice as enshrined in Article 6 European Convention on Human Rights (ECHR) and Article 47 Charter of Fundamental Rights of the European Union (CFR).

In response to the ills of existing redress mechanisms, an emerging trend of consumer alternative dispute resolution (ADR) and consumer online dispute resolution (ODR) schemes has been identified throughout the Member States (MS) aimed to offer consumers a swift, cheap and simple procedure through which they can enforce their rights. Alongside the development at the MS level, the EU policy-makers have developed a wide set of legislative and non-legislative tools with the purpose to make the enforcement of consumer rights within the MS more effective. ${ }^{4}$ A key component of this so-called 'EU enforcement toolbox' is consumer ADR/ODR. ${ }^{5}$ This paper outlines the EU approach to Consumer ADR/ ODR, gives some observations of the functioning of the legislation in practice and concludes with some thoughts for the future.

\section{The EU Level of Consumer ADR/ODR: The ADR Directive 2013/11 and the ODR Regulation 524/2013}

Based on the main rationale of further promoting e-commerce and strengthening the EU internal market (access to justice was only a secondary aim), the EU adopted two binding and complementary instruments in 2013: The ADR Directive $2013 / 11^{6}$ and the ODR Regulation $524 / 2013^{7}$. They are the first binding legislation on Consumer ADR and ODR on the EU level, following a set of non-bind-

3 European Commission, 'Commission Staff Working Paper Impact Assessment accompanying the document Proposal for a Directive of the European Parliament and of the Council on Alternative Dispute Resolution for consumer disputes (Directive on consumer ADR) and Proposal for a Regulation of the European Parliament and of the Council on Online Dispute Resolution for consumer disputes (Regulation on consumer ODR), SEC(2011) 1408 final, p. 5.

4 European Commission, 'Report from the Commission to the European Parliament, the Council and the European Economic and Social Committee on the application of Directive 2013/11/EU of the European Parliament and of the Council on Alternative dispute resolution for consumer disputes and Regulation (EU) No 524/2013 of the European Parliament and of the Council on online dispute resolution for consumer disputes', COM (2019) 425 final, p. 1.

5 European Commission, 'Report from the Commission to the European Parliament, the Council and the European Economic and Social Committee on the application of Directive 2013/11/EU of the European Parliament and of the Council on Alternative dispute resolution for consumer disputes and Regulation (EU) No 524/2013 of the European Parliament and of the Council on online dispute resolution for consumer disputes', COM (2019) 425 final, p. 1.

6 Directive 2013/11/EU of the European Parliament and of the Council on alternative dispute resolution for consumer disputes and amending Regulation (EC) No 2006/2004 and Directive 2009/22/EC (Regulation on Consumer ODR), OJ L 165, 18.6.2013, p. 1.

7 Regulation (EU) No 524/2013 of the European Parliament and of the Council on online dispute resolution for consumer disputes and amending Regulation (EC) No 2006/2004 and Directive 2009/22/EC (Regulation on consumer ODR), OJ L 165, 18.6.2013, p. 1. 
ing instruments that brought limited result due to the non-binding character of these Recommendations. ${ }^{8}$

\subsection{The Consumer ADR Directive 2013/11}

The Consumer ADR Directive 2013/11 promotes a comprehensive array of quality consumer ADR entities operating across the EU and available in all sectors (full coverage). ${ }^{9}$ Its scope includes ADR entities meaning "any entity, however named or referred to, which is established on a durable basis and offers the resolution of a dispute through an ADR procedure and that is listed in accordance with Article 20(2)".${ }^{10}$ Recital 23 of the ADR Directive 2013/11 excludes from the scope procedures before consumer-complaint handling systems operated by the trader as well as direct negotiations between the parties. ${ }^{11}$

Three main deficiencies that the EU aimed to tackle with the legislation was to counter the uneven availability, quality and awareness of Consumer ADR/ODR schemes.

Availability: By obliging MS to create consumer ADR entities for every type of dispute and both cross-border and domestic (full coverage), the EU aimed to counter the significant differences in availability of consumer ADR/ODR regarding both the geographical and sectoral coverage. As such, where some MS had schemes available covering only part of the territory or covering only specific sectors of the retail markets, other MS offered a much wider scope. ${ }^{12}$

Quality: By setting core quality standards for consumer ADR/ODR entities, the EU aimed to tackle the uneven quality of consumer ADR/ODR entities throughout the EU. ${ }^{13}$ Consumer ADR/ODR entities complying with these standards get certified by the competent authority in their MS, and to keep this certification they are regularly monitored by these authorities on their compliance with the quality standards. ${ }^{14}$

Awareness: By posing information requirements on traders, government agencies and consumer ADR/ODR entities, the EU aimed to tackle the low awareness among consumers and traders about the availability of Consumer ADR/ODR entities as well as the insufficient availability of information. ${ }^{15}$ Article 5(2)(a) ADR Directive 2013/11 obliges MS to ensure that ADR entities maintain an upto-date website offering easy access to information. Article 14 of the ODR Regula-

Commission Recommendation 98/257/EC on the principles applicable to the bodies responsible for the out-of-court settlement of consumer disputes, OJ L 115, 17.04.1998; Commission Recommendation 2001/310/EC on the principles of out-of-court bodies involved in the consensual resolution of consumer ADR, OJ L 109, 19.4.2001.

9 See also E.M. van Gelder and A.B. Biard, 'The Online Dispute Resolution Platform after One year of Operation: A work in Progress with Promising Potential', TvC 2018(2).

10 Art. 1 (h) Consumer ADR Directive 2013/11.

11 Recital 23 Consumer ADR Directive 2013/11.

12 European Commission (n. 6), p. 6.

13 European Commission (n. 6) p. 25.

14 Recital 55 Consumer ADR Directive 2013/11.

15 European Commission (n. 6), p. 10. 
tion 524/2013 enshrines the obligation for online traders and marketplaces to provide a link to the ODR platform on their website. ${ }^{16}$

\subsection{The ODR Regulation 524/2013}

The ODR Regulation 524/2013, which became operational in February 2016, is complementary to the Consumer ADR Directive 2013/11 and builds upon its architecture envisioning an EU wide-ODR platform for domestic and cross-border online transactions. The regulation is based on the rationale that there was a lack of mechanisms allowing consumers and traders to resolve disputes via electronic means. The ODR platform connects the disputing parties with nationally certified consumer ADR/ODR entities.

Article 2 of the ODR Regulation 524/2013 defines its scope "contractual obligations stemming from online sales or service contract between a consumer resident in the Union and a trader established in the Union". Recital 14 of the ODR Regulation 524/2013 defines an online sales or service contract as "a sales or service contract where the trader, or the trader's intermediary, has offered goods or services through a website or by other electronic means and the consumer has ordered those goods or services on that website or by other electronic means". An offline contract is thus excluded from the scope of the ODR Regulation 524/2013 and thereby offline claims cannot be brought to the EU ODR platform.

How does the ODR platform work? Consumers fill in an online complaint form (available in all EU languages) on the website of the EU ODR platform. ${ }^{17}$ When the online complaint form is completed it is sent automatically to the trader via the platform. ${ }^{18}$ The trader has three options: to solve the claim bilaterally, to solve the claim through the ODR platform or to choose not to participate. If both parties agree to solve the claim through the ODR platform (30 days' deadline), the complaint is sent to the consumer ADR/ODR entity that the parties agree on, and the Consumer ADR/ODR entity has 90 days to resolve the claim. ${ }^{19}$

\section{Some Observations of the Consumer ADR Directive 2013/11 and the ODR Regulation 524/2013 Functioning in Practice}

This paragraph sets out several observations made, categorized according to the three main aims of the legislation: increasing the availability of high-quality certified consumer ADR/ODR entities and encouraging their use. ${ }^{20}$ 


\subsection{Availability}

To date, all MS have full coverage of certified consumer ADR/ODR entities and a total of 460 certified consumer ADR/ODR entities, including Liechtenstein and Norway, ${ }^{21}$ are notified. Viewing the current landscape of Consumer ADR/ODR on a MS level, however, a scattered and fragmented framework still can be identified.

This can be partly explained by the fact that outside the certified schemes, there is variety of Consumer ADR/ODR schemes available to consumers. As the market is increasingly responding to the pressing need of consumers for simple, cheap and fast redress schemes, there is a proliferation of private-initiative ODR providers offering online options for consumers to gain redress. ${ }^{22}$ An example are dispute resolution mechanisms offered by payment service providers such as Paypal. ${ }^{23}$ Private providers however, often enjoy more regulatory leeway. The question rises if and to what extent out-of-court private ODR schemes such as Paypal, also must comply with a level of quality standards to protect the consumer from their typical weaker position against a trader. Consumers often do not understand the difference between non-regulated and regulated schemes therefore increasingly ending up within a dispute resolution process that is not, or to a lesser extent complying with due process principles. As mentioned above, complaint procedures by the trader are excluded from the scope of the EU legislation as well as direct negotiations between consumer and trader.

In addition, the certified consumer ADR/ODR landscape still varies widely in terms of inter alia dispute resolution processes offered (arbitration, bindend advies, Ombudsman schemes, mediation).

Also, there is a wide variety in terminology used by consumer ADR/ODR schemes. For example, consumer ADR/ODR schemes with 'consumer' in the name, can lead to the perception that this ODR scheme acts in favour of the consumer and therefore traders refrain from participating.

In sum, the scattered landscape of consumer ADR/ODR schemes results in a two-tiered landscape of regulated and non-regulated Consumer ADR/ODR schemes, influences the perception and understanding of the role of Consumer ADR/ODR schemes and risks a higher level of consumer confusion.

\subsection{Awareness}

The information available for consumers on Consumer ADR/ODR is often patchy and disorganized. Much information is provided on the websites of certified Consumer ADR/ODR schemes, but this information often only constitutes abstract statistics within Annual Reports and does not really provide understandable information where consumers are often looking for.

Only $28 \%$ of the traders comply with the information requirements of including a link to the EU ODR platform in their email correspondence with

21 Liechtenstein and Norway are not Member States of the European Union.

22 See also P.M.P. Frenken, 'ODR-procedures bij platformen: laagdrempelig voor consumenten, maar zonder waarborgen voor legaliteit en procedurele rechtvaardigheid', TvC 2019/5.

23 Christoph Busch and Simon Reinhold, 'Standardisation of Online Dispute Resolution Services: Towards a More Technological Approach’, EuCML 1-2, 2015, p. 51. 
traders. ${ }^{24}$ Surveys undertaken in the Netherlands and Belgium show that most consumers indeed do not reach the ODR sites via traders, but by self-searching on the Internet. ${ }^{25}$

\subsection{Quality}

Case studies conducted in the Netherlands and the UK with certified Consumer $\mathrm{ADR} / \mathrm{ODR}$ schemes highlighted the experience that the quality requirements laid down in the Consumer ADR Directive 2013/11 are often perceived to be too broad leading to confusion about the correct interpretation of these requirements. The risk is that it may lead to an inconsistent interpretation of the requirements among different certified Consumer ADR/ODR schemes, therefore resulting in an uneven level of quality.

Furthermore, differences within the review process by competent authorities to certify can lead to an uneven level of quality. As such, on the one hand, there are competent authorities that might briefly review the information submitted by applicants and their review merely regards a 'tick the box' exercise, while on the other hand there are competent authorities that conduct an in-depth assessment of quality requirements. ${ }^{26}$

Moreover, as uniform technological standards for Consumer ODR schemes are lacking on an EU level, this risks the creation of an uneven quality of Consumer ODR schemes and can prevent inter alia a smooth interconnection between different consumer ADR/ODR schemes communicating online as well as sharing documents online. As Busch and Reinholds argue "a due process is not only determined by legal but also by technological aspects.... Law and technology for ODR services form a unit". ${ }^{27}$ Technology is accelerating fast, and an increased use of AI tools and algorithms can be identified to inter alia fulfil tasks as identifying patterns within the market. These developments raise questions on how to regulate the use of $\mathrm{AI}$ in order to accurately protect the consumer.

24 See statistics: European Commission, 'Report from the Commission to the European Parliament, the Council and the European Economic and Social Committee on the application of Directive 2013/11/EU of the European Parliament and of the Council on alternative dispute resolution for consumer disputes and Regulation (EU) No 524/2013 of the European Parliament and of the Council on online dispute resolution for consumer disputes', $\operatorname{COM}(2019) 425$ final, p. 16.

25 A. Biard, S. Voet, K. Hanemaaijer and E. van Gelder, 'Ervaringen en verwachtingen van consumenten over de Consumentenombudsdienst/Service de Médiation pour le Consommateur. Onderzoek naar onvolledige dossiers', July 2019, p. 9; E.M. van Gelder and M.M. de Groot, Perceptions of Consumers with online claim tools: a Dutch case-study of Klachtenkompas.nl, forthcoming March 2020.

26 Alexandre Biard, 'Impact of Directive 2013/11/EU on Consumer ADR Quality: Evidence from France and the UK, Journal of Consumer Policy: Consumer Issues in Law, Economics and Political Science, 2018, p. 113.

27 Busch and Reinhold, 2015, p. 51. 


\section{Results of the Functioning of the ODR Platform}

Since the launch of the ODR platform, 120.000 consumer disputes have been submitted. About $56 \%$ are domestic, $44 \%$ cross-border. About $2 \%$ of the disputes reached a Consumer ADR body through the ODR platform. In around $80 \%$ of the disputes submitted to the ODR platform, the case was closed within the 30 day period. About $42 \%$ of these disputes were solved bilaterally between the trader and consumer. ${ }^{28}$

So what we see is that the ODR platform mainly has an incentive effect on the trader to resolve the claim when notified by the EU commission. As such, the ODR platform in practice is not more than an online referral tool, channelling complaints to offline certified consumer ADR schemes. ${ }^{29}$ The ODR platform is a work in progress, with a promising potential. ${ }^{30}$

\section{Thoughts for the Future}

This paragraph gives some thoughts for the future on how to enhance the awareness and quality.

\subsection{Awareness}

In order to improve the compliance of traders with their information requirements, better information provision towards traders - especially SME's - is needed notifying them about these requirements and explaining how to comply with them. Furthermore, the monitoring of information requirements by the competent authorities may be strengthened.

Another thought may be to recommend the MS to create a single online entry point on the national level that is easily accessible and serves the provision of information to consumers. This entry point should offer tailored information about the possibilities the consumer has as well as navigate the consumer to the correct consumer ADR/ODR scheme competent to resolve their dispute.

\subsection{Quality}

In order to mitigate the confusion regarding the interpretation of quality requirements laid down in the consumer ADR Directive 2013/11, more detailed obligations to comply with the quality requirements may be given.

Also, in order to answer to the novel challenges evoked by the digital context, these quality requirements' must be adjusted to the online environment taking into account challenges such as data ownership, data bias, data protection and security. As such, the current EU consumer ADR/ODR legislation lacks an explanation for the procedure and design of specifically consumer ODR services. ${ }^{31}$ The

28 European Commission (n. 28), p. 14.

29 See also Pablo Cortes, 'The New Landscape of Consumer Redress', in: Pablo Cortes, The New Regulatory Framework for Consumer Dispute Resolution, 2016, p. 19.

30 See also Van Gelder and Biard, 2018.

31 Busch and Reinhold, 2015, p. 50. 
implementation of EU legislation on consumer ODR thus calls for a more integrated approach of legal and technological aspects. This need is further stressed by the role of Consumer ODR schemes gaining an increased public function and thereby the compliance with due process principles becomes more important. Although ODR emerged as a form of dispute resolution using technology to add on to traditional ADR procedures, a move towards a more autonomous form of dispute resolution can be identified using 'disruptive' technologies. It calls into question what quality standards must be in place for consumer ODR schemes to safeguard an accurate protection of the consumers' position, taking into account the specific challenges consumers face within a digital context in order to also safeguard the technological quality of an ODR scheme. An analysis of how the quality standards of the ADR Directive 2013/11 should be interpreted to live up to the technological challenges falls beyond the scope of the paper.

\subsection{The ODR platform}

The incentive effect of the ODR platform proves the want of consumers and traders to solve the claim bilaterally (42\%). In addition, data shows that consumers often just want an apology from the trader instead of enforcing their right through a full-fledged dispute resolution process. ${ }^{32}$ This may substantiate the argument to include an online negotiation phase within the EU ODR platform which automatically connects the trader and consumers and offers them an online negotiation platform within the infrastructure of the EU ODR platform. The European Commission already expressed its intention to further improve the ODR platform, making it better respond to the needs of its users providing more targeted information, directing users to the appropriate redress schemes and facilitating direct settlements. ${ }^{33}$

Furthermore, in order to improve the uptake of the EU ODR platform, the added value can be to go beyond dispute resolution to become a useful data gathering tool to increase policy and regulatory intervention. Big data analytics techniques enable the identification of underlying patterns in the market and can be used to identify failed sectors and issues within the consumer market. ${ }^{34}$

As mentioned above, the ODR platform limits its scope to online sales and service contracts. While this makes sense as the main aim was to stimulate the ecommerce within the internal market, in reality there is still a considerable number of consumers involved in offline contracts, including cross-border offline contracts. It raises the question whether the scope of the ODR platform can be broadened to include offline sales or services contract.

32 Van Gelder and De Groot, forthcoming March 2020.

33 See statistics: European Commission, 'Report from the Commission to the European Parliament, the Council and the European Economic and Social Committee on the application of Directive 2013/11/EU of the European Parliament and of the Council on alternative dispute resolution for consumer disputes and Regulation (EU) No 524/2013 of the European Parliament and of the Council on online dispute resolution for consumer disputes' COM(2019) 425 final, p. 17. 